\title{
Analysis of Principal Component Regression Equations of Air Transportation and Local Economy: Taking Tianjin as an Example
}

\author{
Yanhua Li1 ${ }^{*}$, Yuan Zhang², Tianyi Liu³ \\ ${ }^{1}$ School of Economics and Management, Civil Aviation University of China, Tianjin, China \\ ${ }^{2}$ China Aviation Industry Planning Design and Research Institute, Beijing, China \\ ${ }^{3}$ University of Liverpool, Liverpool, UK \\ Email: *yhlicauc@126.com
}

How to cite this paper: Li, Y.H., Zhang, Y. and Liu, T.Y. (2018) Analysis of Principal Component Regression Equations of Air Transportation and Local Economy: Taking Tianjin as an Example. Theoretical Economics Letters, 8, 1830-1839. https://doi.org/10.4236/tel.2018.810120

Received: March 28, 2018

Accepted: June 18, 2018

Published: June 21, 2018

Copyright $\odot 2018$ by authors and Scientific Research Publishing Inc. This work is licensed under the Creative Commons Attribution International License (CC BY 4.0).

http://creativecommons.org/licenses/by/4.0/

\begin{abstract}
The city of Tianjin and the realization of the national development strategy put forward new requirements for air transport. This paper is based on Tianjin air transport and the interaction of regional economic development present situation, analyzed problems of development, analyzed interactive development mechanism of the Tianjin aviation transport and economic, then, extracted the Tianjin aviation transportation and regional economy of main component, and established a principal component regression equation, for air transportation and Regional economy in Tianjin fitness trend prediction, gives countermeasures to promote the development of air transport and Tianjin economic interactions.
\end{abstract}

\section{Keywords}

Air Transport, Regional Economic, The Interactive Development, Principal Component Analysis

\section{Introduction}

In recent years, various researchers in Western countries have published studies aimed at identifying the relationship between air transportation and local economy in different perspectives. Several studies analyze the linkage between investment of air traffic and growth rate of GDP [1] [2] [3] [4].

Frédéric Dobruszkes, Moritz Lennert, Gilles Van Hamme [5] established a regression model in order to examine the determinants of air traffic volume in the major European urban regions, highlighting those that depend on the metropol- 
itan features of cities. This paper found that GDP, the level of economic decision-power, tourism functions, and the distance from a major air market account for more than two-thirds of the variation in air service. Much of the remainder is probably attributable to the specificities of the urban economy, to actors' strategies and to competition from high-speed trains. R. Ramanathan [6] studies the relationship between GDP in India and passenger throughput in the long-term equilibrium by employing the approaches of cointegration theory and establishing error correction model.

Ye Zhou [7] studies the relationship between the development of civil aviation and economic growth by employing the approaches of cointegration theory. Chen Jin-tu [8] uses GDP as a measure of development of economy and used civil aviation total throughput as a measure of rapid of civil aviation industry. Liu Ying [9] have chosen to analyze the relationship of civil transport increasing rate and GDP growth rate. Liu Xue-ni, Ning Xuan-xi and Zhang Dong-qing [10] examines the causality between civil aviation transportation and economic growth in Beijing, Tianjin, Hebei, Changjiang River delta and Pearl River delta. The result shows that although there is only a unidirectional causality between the aviation transportation and economic growth at national level, the relationships at regional level are different. Zhao Gui-hong [11] puts Tianjin in Beijing-Tianjin-Hebei economic zone to forecast passengers and freights handled at Tianjin airport by the means of linear regression.

Jing Guang-lei, Li Ming, Jiang Liang, Pan Xiao-ling, Qin Yi, Chen Xuan-bing, $\mathrm{Hu}$ Jie [12] clarifies the connotation of coordination development which starts from the application of the analysis of coordination theory in coordination development. And the structure, characteristic, interaction of city comprehensive transportation and economy system are analyzed. Then the inner character and coordination principle of city traffic and economy system are present. Yang Wei and Yang $\mathrm{Ka}$ [13] focuses on the economics of airport. It examines advantages enjoyed by passengers having access to a major airport as well as the economic benefits that accrue to a city or geographical region that is host to a major airport, especially a hub airport. In particular, it looks into the linkages between airport-related activities and local economic development. Airports essentially have four potential types of impact on the regional economy: the primary, secondary, tertiary and perpetuity effects of airports.

However, we notice that most research is on general quantity, including GDP, investment of social fixed assets, passenger traffic, feight traffic, total throughput, passenger throughput, freight throughput and so on. So that there is a lack of research on relatively micro-region's air transport and regional economic interaction research.

Moreover, the method applied most is establishing multiple linear regression model. When dealing with many variables, variables are always related, causing multicolinearity. In the presence of multicollinearity, the estimate of one variable's impact on the dependent variable while controlling for the others tends to be less precise than if predictors were uncorrelated with one another. In some 
sense, the collinear variables contain the same information about the dependent variable. If nominally "different" measures actually quantify the same phenomenon, then they are redundant. Alternatively, if the variables are accorded different names and perhaps employ different numeric measurement scales but are highly correlated with each other, then they suffer from redundancy.

There are many variables for us to take into consideration to analyze interaction between local economy and air transport. We expect to use "comprehensive variables" instead of original variables so that we can use less variables to indicate information as much as possible. Based on this reduced-dimensional thinking, this paper applies principle component analysis and principal component regression to put forward policy recommendations to coordinate the development of air transport and local economy.

\section{Methods of Analysis}

\subsection{Principal Component Analysis (PCA)}

PCA is considered the oldest technique in multivariate analysis and was first generalized by Hotelling in 1933. PCA is a method that reduces the dimensionality of a dataset, by finding a new set of variables, smaller than the original set of variables. This efficient reduction of the number of variables is achieved by obtaining orthogonal linear combinations of the original variables-the so-called Principal Components (PCs). PCA is useful for the compression of data and to find patterns in high-dimensional data.

The mathematical equation for PCA are presented below.

We consider a set of $n$ observations on a vector of $p$ variables organized in a matrix $X(n \times p)$ :

$$
\left\{x_{1}, x_{2}, \cdots, x_{n}\right\} \in \mathfrak{R}^{p} .
$$

The PCA method finds $p$ artificial variables (principal components). Each principal component is a "linear combination of $X$ matrix columns, in which the weights are elements of an eigenvector to the data covariance matrix or to the correlation matrix, provided the data are centered and standardized". The principal components are uncorrelated.

The first principal component of the set by the linear transformation is:

$$
z_{1}=a_{1}^{T} x_{j}=\sum_{i=1}^{p} a_{i 1} x_{i j}, j=1, \ldots, n .
$$

In Equation (2), the vectors $a_{1}$ and $x_{j}$ are:

$$
\begin{aligned}
& a_{1}=\left(a_{11}, a_{21}, \ldots, a_{p 1}\right) \\
& x_{j}=\left(x_{1 j}, x_{2 j}, \ldots, x_{p j}\right) .
\end{aligned}
$$

One chooses $a_{1}$ and $x_{j}$ such as the variance of $z_{1}$ is maximum. All principal components start at the origin of the ordinate axes. First PC is direction of maximum variance from origin, while subsequent PCs are orthogonal to first PC and describe maximum residual variance. 


\subsection{Principal Component Regression (PCR)}

Economic variables are highly correlated. Multicollinearity is a statistical phenomenon in which two or more predictor variables in a multiple regression model are highly correlated. In this situation the coefficient estimates may change erratically in response to small changes in the model or the data. It affects calculations regarding individual predictors. That is, a multiple regression model with correlated predictors can indicate how well the entire bundle of predictors predicts the outcome variable, but it may not give valid results about any individual predictor, or about which predictors are redundant with respect to others. Principal component regression can be used as a remedy for multicollinearity.

In statistics, principal component regression (PCR) is a regression analysis that uses principal component analysis when estimating regression coefficients. It is a procedure used to overcome problems which arise when the exploratory variables are close to being colinear.

In PCR instead of regressing the independent variables (the regressors) on the dependent variable directly, the principal components of the independent variables are used. One typically only uses a subst of the principal components in the regression, making a kind of regularized estimation.

PCR (principal components regression) is a regression method that can be divided into three steps: the first step is to run a principal components analysis on the table of the explanatory variables. The second step is to run an ordinary least squares regression (linear regression) on the selected components: the factors that are most correlated with the dependent variable will be selected. Finally the parameters of the model are computed for the selected explanatory variables.

\section{Linking Urban Areas to Patterns in Air Service: Hypotheses and Data}

Air transportation services and economic development interact with each other through a series of mutualcausality feedback relationships. Reviewing the recent literature [14] [15] [16] [17] [18], this paper describes the mechanisms to identify the relevant factors influencing this interaction.

Air transportation provides employment in the aviation sector and creates wider socioeconomic benefits through its potential to enable certain types of activities in a local economy. As a result, the availability of air transportation services effectively increases the scope and cycle time of economic activity. The economic impacts of air transport include:

\subsection{Direct Impacts}

These cover employment and activity within the air transport industry including airline and airport operations, aircraft maintenance, air traffic control and regulation, and activities directly serving air passengers, such as check-in, baggage-handling, on-site retail and catering facilities. Not all of these activities 
necessarily take place at an airport, with some taking place at head office. Direct impacts also include the activities of the aerospace manufacturers selling aircraft and components to airlines and related businesses.

\subsection{Indirect Impacts}

These include employment and activities of suppliers to the air transport industry, for example, jobs linked to aviation fuel suppliers; construction companies that build additional facilities; the manufacture of goods sold in airport retail outlets, and a wide variety of activities in the business services sector (call centres, IT, accountancy, etc.).

\subsection{Induced Impacts}

These include spending by those directly or indirectly employed in the air transport sector that supports jobs in industries such as retail outlets, companies producing consumer goods and a range of service industries (e.g. banks, restaurants, etc.).

\subsection{Catalytic Impacts}

The air transport industry's most important economic contribution is through its impact on the performance of other industries and as a facilitator of their growth. It affects the performance of the world economy, improving the efficiency of other industries across the whole spectrum of economic activity-referred to as catalytic or "spin-off" benefits.

The region's economic activity in turn generates the need for passenger travel and freight and drives the demand for air transportation services.

Practically, we will thus choose indicators of local economy in terms of the economic impacts of air transport (Figure 1). And several variables have been identified as indicators of air transport likely to describe its scale and efficiency.

\section{Case Study}

With the Binhai New Area was included in the national development strategy, the Binhai New Area has played a leading role in the Bohai Sea region. A320 plane assembly line, being the first aircraft assembly line outside Europe and the first one in Asia, was established in Tianjin in 2006. With the help of Tianjin government, Hainan Airlines started Tianjin airlines, being local airlines of Tianjin. In these new circumstances, it is imperative to have a good knowledge of the interaction between air transport and regional economy. With the available data, qualitative analysis and scientific computing, we hope to make a better understanding of interaction between economic development and air transport in Tianjin. So that we could put forward policy recommendations to coordinate the development of Tianjin air transport and local economy. This paper presents a case study of Tianjin.

Reviewing the recent literature, we select the following variables on the basis 


\section{Direct}

(within the industry)

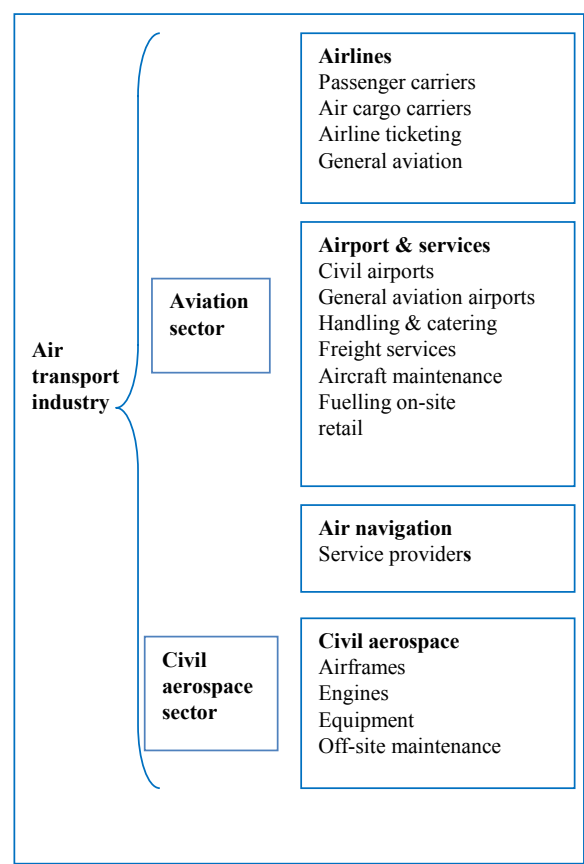

Indirect/induced

(industry supply chain)

\section{Suppliers}

Off-site fuel suppliers

Food \& beverage

Construction

Manufacturing

Computers/electronics

Retail goods$$
\rightarrow
$$

Business services

Call centres

Accountants

Lawyers, banks

Computer software

Catalytic effects

(impacts on other industries)

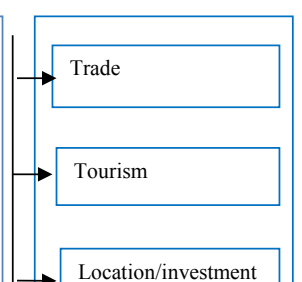

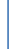

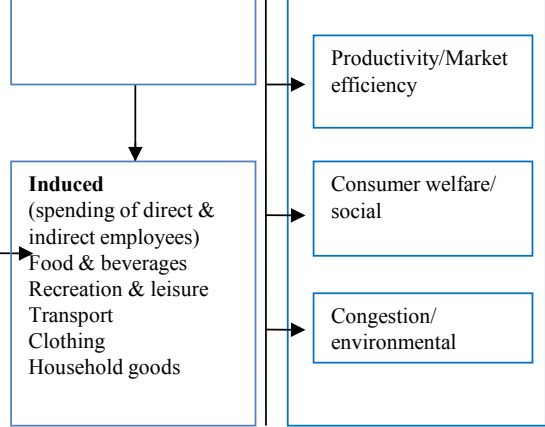

Figure 1. The air transport industry and its economic impacts [19].

of available data and the purpose of this paper, yielding a sample that ranges from the year 2000 to 2010 . They consist of (see Table 1 for details):

The software package used in this case is SPSS. We obtain the results as follows:

In Table 2 the cumulated percent in variation explained by the first factor of Tianjin air transport is as much as $99.278 \%$ and that of local economy reaches 94.767\%. Therefore, we choose respectively one factor from both sides. And these two factors can be used further as predictors.

From the component matrices (Table 3), we get the principal component equations as follows:

$$
Z_{1}=\frac{0.996}{\sqrt{1.986}} X_{1}^{*}+\frac{0.996}{\sqrt{1.986}} X_{2}^{*}
$$

and

$$
\begin{aligned}
V_{1}= & \frac{0.998}{\sqrt{8.529}} Y_{1}^{*}+\frac{0.885}{\sqrt{8.529}} Y_{2}^{*}+\frac{0.996}{\sqrt{8.529}} Y_{3}^{*}+\frac{0.995}{\sqrt{8.529}} Y_{4}^{*}+\frac{0.999}{\sqrt{8.529}} Y_{5}^{*} \\
& +\frac{0.943}{\sqrt{8.529}} Y_{6}^{*}+\frac{0.974}{\sqrt{8.529}} Y_{7}^{*}+\frac{0.997}{\sqrt{8.529}} Y_{8}^{*}+\frac{0.969}{\sqrt{8.529}} Y_{9}^{*}
\end{aligned}
$$

Specifically, we can regard the variable $Z_{1}$ as standardized principal component of the air transportation variables selected. And we define $X_{1}^{*}, X_{2}^{*}$ separately as standardized variables of $X_{1}, X_{2}$.

Furthermore, we regard the variable $V_{1}$ as standardized principal component of the local economy variables selected. And we define $Y_{1}^{*}, Y_{2}^{*}, Y_{3}^{*}, Y_{4}^{*}, Y_{5}^{*}$, 
Table 1. The index system of air transportation and local economy.

\begin{tabular}{cc}
\hline & Variables \\
\hline Air transportation & Passenger traffic (10 000 persons): $x_{1}$ \\
& Freight traffic (10 000 tons): $x_{2}$ \\
Local economy & Gross domestic product of Tianjin (100 million yuan): $y_{1}$ \\
& Total value of imports \& exports in foreign trade (USD 100 million): $y_{2}$ \\
Total government revenue (100 million yuan): $y_{3}$ \\
Number of employment personnel (10,000 persons): $y_{4}$ \\
\hline
\end{tabular}

Table 2. Initial eigenvalues, variance proportion and cumulative proportion of principal components of air transportation in Tianjin and local economy.

\begin{tabular}{ccccc}
\hline & \multicolumn{2}{c}{ Air transportation } & \multicolumn{2}{c}{ Local economy } \\
\hline Principal component & 1 & 2 & 1 & 2 \\
Total & 1.986 & 0.014 & 8.592 & 0.345 \\
\% of Variance & 0.993 & 0.007 & 0.948 & 0.038 \\
Cumulative \% & 0.993 & 1.000 & 0.948 & 0.986 \\
\hline
\end{tabular}

Table 3. Component matrices of principal components of air transportation in Tianjin and local.

\begin{tabular}{cccc}
\hline $\begin{array}{c}\text { Variables of air } \\
\text { transportation }\end{array}$ & $\begin{array}{c}\text { Component matrix of } \\
Z_{1}\end{array}$ & $\begin{array}{c}\text { Variables of local } \\
\text { economy }\end{array}$ & $\begin{array}{c}\text { Component matrix of } \\
V_{1}\end{array}$ \\
\hline$X_{1}$ & 0.996 & $Y_{1}$ & 0.998 \\
$X_{2}$ & 0.996 & $Y_{2}$ & 0.885 \\
& $Y_{3}$ & 0.996 \\
& $Y_{4}$ & 0.995 \\
& $Y_{5}$ & 0.999 \\
& $Y_{6}$ & 0.943 \\
& $Y_{7}$ & 0.974 \\
& $Y_{8}$ & 0.997 \\
& $Y_{9}$ & 0.969 \\
\hline
\end{tabular}

$Y_{6}^{*}, Y_{7}^{*}, Y_{8}^{*}, Y_{9}^{*}$ separately as standardized variables of $Y_{1}, \ldots, Y_{9}$.

We regress the component $V_{1}$ on the standardized variable $X_{1}^{*}$. Regression analysis yields the following results:

From the results given in Table 4, the fit of this model is very high. Because Significance $\mathrm{F}$ and Significance $\mathrm{T}$ are both nearly to 0 , the model is valid and the variable $V_{1}$ is linearly related to $x_{1}^{*}$. Hence

$$
x_{1}^{*}=0.998 V_{1}
$$

We can now obtain the following relation from Equation (1):

$$
\begin{aligned}
x_{1}= & -1315.17+0.030 y_{1}+0.266 y_{2}+0.117 y_{3}+0.899 y_{4} \\
& +0.002 y_{5}+0.560 y_{6}+0.264 y_{7}+0.014 y_{8}
\end{aligned}
$$


Table 4. Regression results of principal component regression analysis.

\begin{tabular}{|c|c|c|}
\hline Statistics & \multicolumn{2}{|c|}{ Results } \\
\hline R Square & \multicolumn{2}{|c|}{0.997} \\
\hline Adjusted R Square & \multicolumn{2}{|c|}{0.997} \\
\hline Std. Error of the Estimate & \multicolumn{2}{|c|}{0.05509688} \\
\hline $\mathrm{F}$ & \multicolumn{2}{|c|}{ Sig. } \\
\hline 3284.170 & \multicolumn{2}{|c|}{0.000} \\
\hline Standardized Coefficient & $\mathrm{t}$ & Sig. \\
\hline 0.998 & 57.308 & 0.000 \\
\hline
\end{tabular}

Furthermore, we get a series of principal component regression equations in the same methods as follows:

$$
\begin{gathered}
x_{2}=-32.189+0.001 y_{1}+0.007 y_{2}+0.003 y_{3} \\
+0.024 y_{4}+0.015 y_{6}+0.007 y_{7} \\
y_{1}=-935.302+7.872 x_{1}+296.866 x_{2} \\
y_{2}=15.011+0.721 x_{1}+27.180 x_{2} \\
y_{3}=-447.736+2.045 x_{1}+77.103 x_{2} \\
y_{4}=392.406+0.266 x_{1}+10.046 x_{2} \\
y_{5}=-21047.9+128.295 x_{1}+4838.016 x_{2} \\
y_{6}=43.128+0.376 x_{1}+14.162 x_{2} \\
y_{7}=-107.882+0.854 x_{1}+32.216 x_{2} \\
y_{8}=2492.769+17.598 x_{1}+663.639 x_{2} \\
y_{9}=-104636+912.498 x_{1}+34410.513 x_{2}
\end{gathered}
$$

It can been seen from Equation (8) and Equation (9) that for each additional 100 million yuan of GDP in Tianjin, passenger traffic increases on the average by 3410 persons and freight traffic increases on the average by 10 tons (assuming the other variables are held constant). So we can conclude that the local economy provides capital and generates demand for passenger and freight travel.

Together, Equations (10), (12), (13), (15) and (17) imply that for each additional 10,000 air passengers, GDP of Tianjin increase on the average by 787 million yuan, total government revenue increases on the average by 205 million yuan, number of employment personnel increases on the average by 2660 persons, per capita annual disposable income of urban households increases on the average by 18 yuan, Gross product of transportation storage and post services increases on the average by 38 million yuan (assuming freight traffic is held constant). Moreover, for each additional 10,000 tons of air cargo, GDP of Tianjin increases on the average by 30 billion yuan, total government revenue increases on the average by 8 billion yuan, number of employment personnel increases on the average by 100,460 persons, per capita annual disposable income of urban households increases on the average by 663.639 yuan, Gross product of trans- 
portation storage and post services increases on the average by 3 billion yuan (assuming passenger traffic is held constant). It is obvious to see that air transport is a significant tax payer and generates employment and wealth.

Furthermore, in Equation (16), for each additional 10,000 air passengers, Gross product of wholesale and retail trade increases on the average by 85 million yuan (assuming freight traffic is held constant). Moreover, for each additional 10,000 tons of air cargo, Gross product of wholesale and retail trade increases on the average by 66 billion yuan (assuming passenger traffic is held constant). Thus, air transport generates wide indirect and induced benefits.

Finally, it can be shown from Equations (11), (15) and (18) that for each additional 10,000 air passengers, total value of imports \& exports in foreign trade increases on the average by USD 72 million, foreign exchange earning from international tourists increases on the average by 13 million, foreign capital actually used increases on the average by USD 91 million (assuming freight traffic is held constant). Moreover, for each additional 10,000 tons of air cargo, total value of imports \& exports in foreign trade increase on the average by USD 3 billion, foreign exchange earning from international tourists increases on the average by USD 48 million, foreign capital increases on the average by USD 344 million (assuming passenger traffic is held constant). Hence, the air transport industry has a substantial catalytic impact.

\section{Conclusions}

Our research presents a principal component model establishing principal component regression equations. Then we apply this model to gaining insight into the relationship between air passenger travel in Tianjin and local economy. Future research should go into further detail by applying the principal component regression equations to forecast so that we shall find the mutual adaptation "gap" of air transport and local economy in the next five years. And thus we shall make relevant policy recommendations in terms of the current development situation and requirements of the new era. Consider the focus of this paper and space limitations, we shall not give relevant details here.

Possible differentiations to study include:

1) In order to better take into account the feedback-based interaction between air transportation and local economy, it could be interesting to use a measure of accessibility to population or to technology within a certain time range around the airport.

2) We illustrate the interaction taking Tianjin area as an example. It could be necessary to use both world-wide and country-level analysis to describe the relationship between air transportation and economic activity.

3) The criteria we take into account for indices selection are the availability of data and the frequency in relevant literature. But it is more scientific and reasonable to use other methods, such as cluster analysis and variance analysis to select variables. It is meaningful to get more comprehensive data to filter out the most suitable indices for evaluation of specific areas. 


\section{References}

[1] Aschauer, A.D. (1989) Is Public Expenditure Productive? Journal of Monetary Economies, 23, 177-200. https://doi.org/10.1016/0304-3932(89)90047-0

[2] Munnell, A.H. (1990) Why Has Productivity Growth Declined? Productivity and Public Investment. New England Economic Journal, 4-22.

[3] Durkin Jr., J.T. and Wassmer, R.W. (1994) Public Infrastructure Spending and Private Generation in Large US Cities. Working Paper, Lincoln Institute of Land Policy, Cambridge.

[4] Holtz-Eakin, D. and Schwartz, A.E. (1995) Infrastructure in a Structural Model of Economic Growth. Regional Science and Urban Economics, 25, 131-151. https://doi.org/10.1016/0166-0462(94)02080-Z

[5] Dobruszkes, F., et al. (2010) An Analysis of the Determinants of Air Traffic Volume for European Metropolitan Areas. Journal of Transport Geography.

[6] Ramanathan, R. (2001) The Long-Run Behaviour of Transport Performance in India: A Cointegration Approach. Transportation Research Part A, 35, 309-320. https://doi.org/10.1016/S0965-8564(99)00060-9

[7] Ye, Z., Li, Z.M. and Li, X.F. (2005) Empirical Research on the Relationship between the Development of China's Civil Aviation and Economic Growth. Journal of Tianjin University of Technology, 21, 81-84.

[8] Chen, J.T. (2005) Effect of the Development of Civil Aviation to Improving National Economy. Journal of Chongqing Polytechnic College, 20, 77-80.

[9] Liu, Y. (2000) An Analysis of the Relationships between the Growth Rate of the Air Traffic Statistics and the Growth Rate of GDP. Forum, 9, 8-10.

[10] Liu, X.N., Ning, X.X. and Zhang, D.Q. (2007) A Comparative Analysis of the Relationship between Civil Aviation Transportation and Economic Growth in Different Regions of China. Management Review, 19, 21-26.

[11] Zhao, G. (2003) Forecasting Actual Passengers and Freights Handled. Economic Geography, 23, 338-341.

[12] Jing, G., Li, M., Jiang, L., Pan, X.-L., Qin, Y., Chen, Y.-B. and Hu, J.-M. (2008) Analysis of Coordination Development of Civil Aviation Transportation and Economy. Air Transport \& Business, No. 7, 4-7.

[13] Song, W. and Yang, K. (2006) The Impacts of Air Transportation and Airport on Regional Economic Development. Scientia Geographica Sinica, 26, 649-657.

[14] Hansman, R.J. (2005) The Impact of Information Technologies on Air Transportation. AIAA Aerospace Sciences Conference, Reno, January 2005, AIAA 2005-0001.

[15] Ishutkina, M.A. and Hansman, R.J. (2010) Analysis of Interaction between Air Transportation and Economic Activity. Working Paper, Massachusetts Institute of Technology, Cambridge.

[16] Air Transport Action Group (ATAG) (2005) The Economic and Social Benefits of Air Transport.

[17] Sun, B., Jin, L.-G. and Cao, Y.-C. (2006) Analysis of Airport Economic Mechanism-Taking Beijing Capital International Airport as an Example. Theoretical Investigation, No. 6.

[18] OEF (2005) Survey Conducted on Behalf of IATA: Measuring Airline Network Benefits.

[19] Oxford Economic Forecasting (OEF) (2004) Survey Conducted on Behalf of IATA: Measuring Airline Network Benefits. 